\title{
Novel Design of High-Gain Planar Dipole-Array Antenna for RFID 2.45 GHz
}

\author{
Danpeng Xie, ${ }^{1}$ Xueguan Liu, ${ }^{1,2}$ Huiping Guo, ${ }^{1}$ and Xinmi Yang ${ }^{1}$ \\ ${ }^{1}$ School of Electronic and Information Engineering, Soochow University, Suzhou, Jiangsu 215000, China \\ ${ }^{2}$ Suzhou Keylab of RF and Microwave Millimeter Wave Technology, Suzhou, Jiangsu 215000, China \\ Correspondence should be addressed to Danpeng Xie; xiedanpeng@gmail.com
}

Received 12 September 2013; Accepted 6 November 2013; Published 30 January 2014

Academic Editor: Rezaul Azim

Copyright (C) 2014 Danpeng Xie et al. This is an open access article distributed under the Creative Commons Attribution License, which permits unrestricted use, distribution, and reproduction in any medium, provided the original work is properly cited.

This paper presents a novel high-gain planar dipole-array antenna for $2.45 \mathrm{GHz}$ which consists of four planar dipole elements placed in two parallel lines. Phase retardation of each element is set by feeding network to form controllable radiation direction. The radiation pattern of the array is discussed according to Arrays Theorem. The measured $-10 \mathrm{~dB}$ band is from $2.3 \mathrm{GHz}$ to $2.57 \mathrm{GHz}$, and peak gain in this band is $7.5 \mathrm{dBi}$. The gain can even reach $10.5 \mathrm{dBi}$ after installing additional ground. The proposed antenna has advantages of high gain, controllable direction, and planarity which are suitable for $2.45 \mathrm{GHz}$ RFID base station.

\section{Introduction}

As an integral part of our life, RFID increases productivity and convenience [1]. It is ubiquitous in solving problems in fields such as supply chain management, security, personal identification, and asset tracking [2]. Low-gain tag antennas are used for transponder, and a high-gain reader antenna is required to increase the reading range [3]. To meet the high-gain demand of RFID base station, antenna arrays are arranged in certain position. With certain matching condition of amplitude and phase of current for each element, the radiation vectors superpose and gain enhances according to Arrays Vector Sum Theorem [4]. Among various kinds of element structure, microstrip and dipole are popularly used to provide high gain. Microstrip antenna has characteristics of easy integration, planar structure, light weight, small size, and low profile. However, it suffers from low directivity, narrow bandwidth typically 5\%, and low efficiency [5]. Dipole-printed antenna is fit for high-gain systems for its wide bandwidth and simple structure [6].

Recently, a composite dipole antenna array with direct feed is discussed [7]. Efficiency and omnidirectional radiation gain are enhanced due to the load of antenna. Another novel omnidirectional antenna with bandwidth broadened is presented [8]. Two half-wavelength dipoles are printed on both sides, and the parasitical elements are connected to the fed ones by metal pins. The antenna is fed by coupled lines.

In this work, a novel high-gain planar dipole-array antenna with wide bandwidth and controllable radiation direction is presented. Dipoles are printed on both sides of the substrate, and all dipoles are fed by CPW line, with advantages of low radiation loss (especially from the feed point), less dispersion, planar configuration, and amenability to integrate with active microwave devices $[9,10]$.

\section{Structure of Proposed Array Antenna}

Structure of proposed antenna is shown in Figure 1. Figure 1(a) presents the structure of four-element arrays which is printed on a substrate with relative permittivity of 4.4, a loss tangent of 0.02 , and a thickness of $h=1.6 \mathrm{~mm}$. Figure 1(b) presents structure of one element. Top layer contains planar coaxial feed lines, radiation dipoles, and ground. Bottom layer is ground with similar dipole structure of top layer. Two rows vias connect upper and lower ground plane. Structure of the coplanar waveguide feeding network is shown in Figure 2, which not only divides power for four ports, but also acts as a phase shifter to make $180 \mathrm{deg}$ phase retardation. In this case, current of arrays has $180 \mathrm{deg}$ phase 


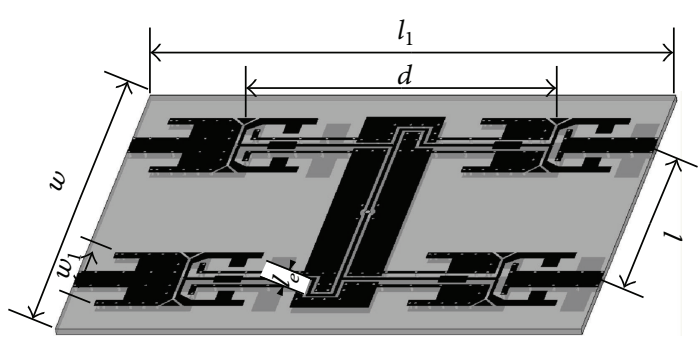

(a)

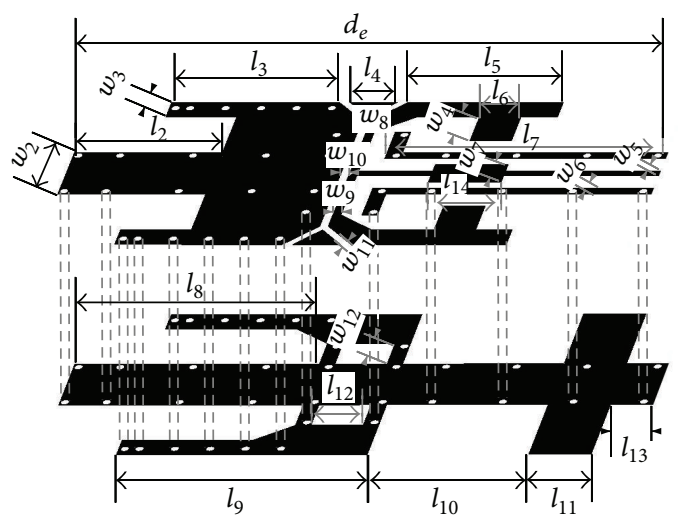

(b)

FIGURE 1: Geometries of the proposed antenna. (a) Four-element arrays and (b) top layer and bottom layer of one element.

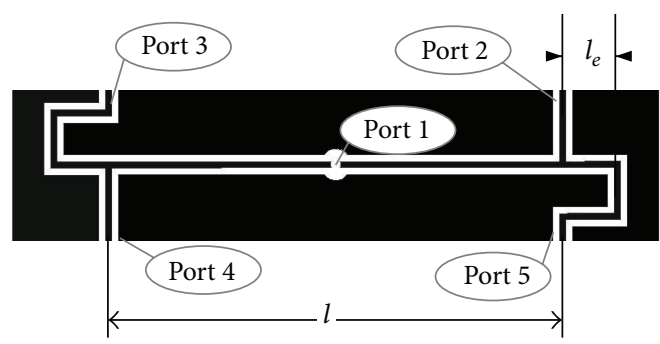

FIGURE 2: Structure of central coplanar waveguide.

TABLE 1: Values of $l$ and $l_{e}$ with 180 deg phase retardation.

\begin{tabular}{lcc}
\hline$l(\mathrm{~mm})$ & $l_{e}(\mathrm{~mm})$ & $\varphi(\mathrm{deg})$ \\
\hline 20 & 10.2 & $179.5 / 179.1$ \\
32 & 9.5 & $179.2 / 179.2$ \\
40 & 9 & $179.2 / 179.3$ \\
48 & 8.4 & $179.5 / 179.7$ \\
60 & 7.2 & $179.5 / 179.7$ \\
\hline
\end{tabular}

retardation with the same direction. By controlling phase retardation of each array, radiation direction is identified. By setting variables $l$ and $l_{e}$, phase retardation can be tuned using Ansoft HFSS. Table 1 lists the possible combinations of $l$ and $l_{e}$ for $180 \mathrm{deg}$ phase retardation. In our design, $l$ and $l_{e}$ are selected as $60 \mathrm{~mm}$ and $7.2 \mathrm{~mm}$.

\section{Analysis of Proposed Arrays Using Arrays Theorem}

In this section, analysis of proposed arrays using Arrays Theorem is given. Firstly, two dipole elements in one line comprise a Binary Side Fire Array. The two Binary Side Fire Arrays with four elements comprise a Binary End Fire Array [11]. For Binary Side Fire Array, assuming that the array distance is half wavelength, namely, $d=\lambda / 2$, and the phase difference of the two elements is $\varphi=90 \mathrm{deg}$, the current relation of the two elements can be expressed as

$$
I_{2}=I_{1} e^{-j \varphi} .
$$

For Binary Side Fire Array, the total far electric field $E_{\theta}$ is expressed as

$$
\begin{aligned}
E_{\theta}= & E_{1 \theta}+E_{2 \theta} \\
= & j \frac{60 I_{1}}{r} \frac{\cos ((\pi / 2) \cos \theta)}{\sin \theta}\left(e^{-j k \Delta k}+\frac{I_{2}}{I_{1}} e^{j k \Delta k}\right) e^{-j k r} \\
= & j \frac{60 I_{1}}{r} \frac{\cos ((\pi / 2) \cos \theta)}{\sin \theta} 2 \cos \left(\frac{k d}{2} \cos \theta-\frac{\varphi}{2}\right) \\
& \times e^{-j k r} e^{-j(\varphi / 2)} .
\end{aligned}
$$

The corresponding radiation direction pattern is

$F(\theta)=\frac{|E|}{E_{M}}=\frac{f(\theta)}{f_{M}}=\frac{\cos ((\pi / 2) \cos \theta)}{\sin \theta} \cos \left(\frac{\pi}{2} \cos \theta-\frac{\pi}{4}\right)$.

For the Binary End Fire Array, the phase retardation of its two elements (i.e., two Binary Side Fire Arrays) is $\gamma=$ $-90 \mathrm{deg}$, and the distance between the elements is $l=\lambda / 2$. Substituting $d=\lambda / 2$ and $\varphi=0 \mathrm{deg}$, the total far electric field of the Binary End Fire Array $E_{\theta}$ is expressed as

$$
\begin{aligned}
E_{\theta}= & E_{1 \theta}+E_{2 \theta}+E_{3 \theta}+E_{4 \theta} \\
= & j \frac{60 I_{1}}{r} \frac{\cos ((\pi / 2) \cos \theta)}{\sin \theta}\left(e^{-j k(r+\Delta r)}+\frac{I_{2}}{I_{1}} e^{-j k(r-\Delta r)}\right) \\
& \times\left(e^{-j k(s+\Delta s)}+\frac{I_{3}}{I_{1}} e^{-j k(s-\Delta s)}\right) \\
= & j \frac{60 I_{1}}{r} \frac{\cos ((\pi / 2) \cos \theta)}{\sin \theta} 4 \cos \left(\frac{k d}{2} \cos \theta-\frac{\varphi}{2}\right) \\
& \times e^{-j k r} e^{-j(\varphi / 2)} \cos \left(\frac{k l}{2} \cos \theta-\frac{\gamma}{2}\right) e^{-j k s} e^{-j(\gamma / 2)} .
\end{aligned}
$$

The final radiation pattern of the four element array is calculated as

$$
F(\theta)=\frac{\cos ((\pi / 2) \cos \theta)}{\sin \theta} \cos \left(\frac{\pi}{2} \cos \theta\right) \cos \left(\frac{\pi}{2} \cos \theta+\frac{\pi}{4}\right) .
$$

The calculated radiation pattern of the four-element array by MATLAB is shown in Figure 3. Main lobe shifts towards 


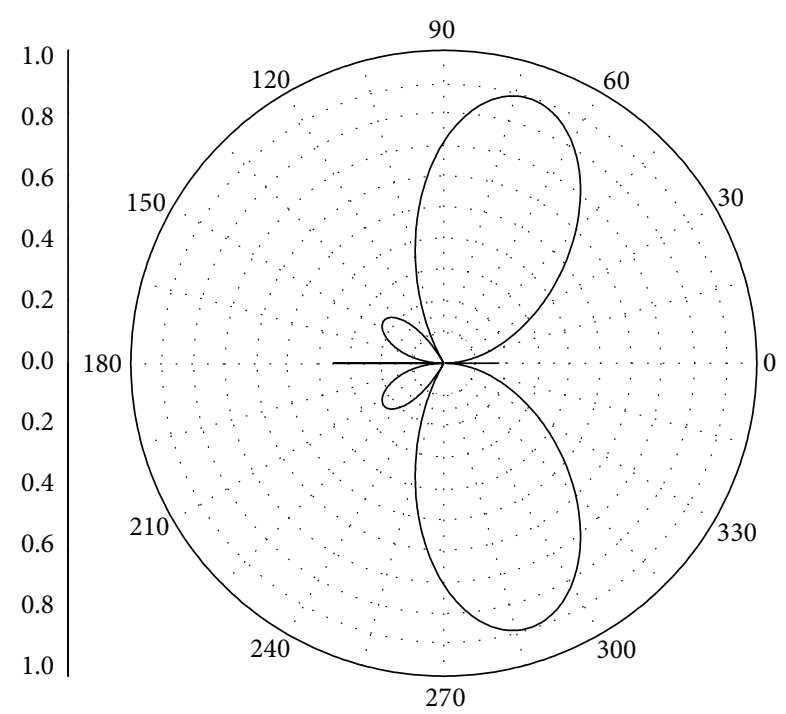

Binary Side Fire Arra

(a)

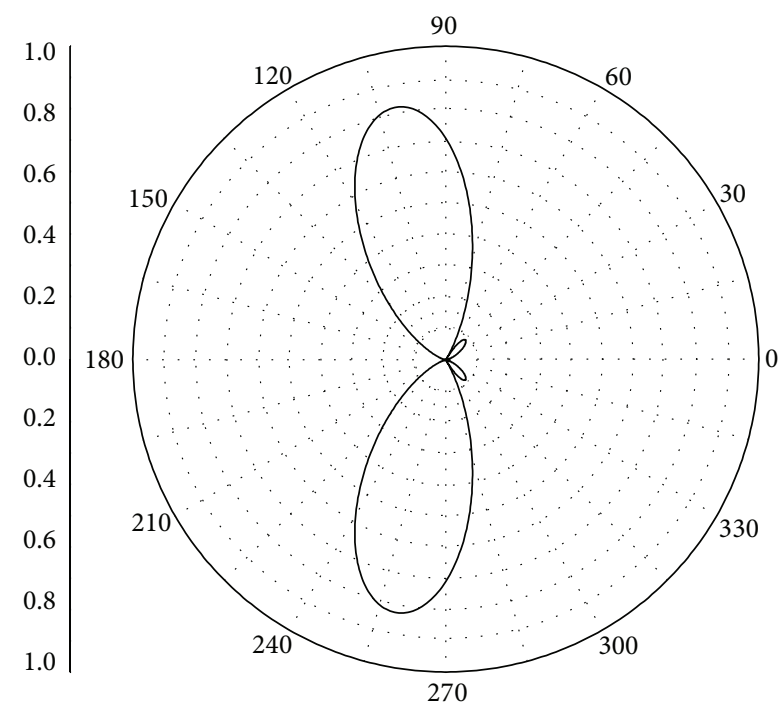

— Binary End Fire Array

(b)

FIGURE 3: Radiation pattern of arrays calculated by MATLAB. (a) Binary Side Fire Array and (b) Binary End Fire Array.

left with side lobe towards right. So by controlling phase of each array $\varphi$ and $\gamma$, radiation direction can be controlled. Hence, the proposed antenna is suitable for base station application with particular beam angle requirement.

\section{Simulated and Measured Result}

The distance of two adjacent arrays in the same row $d$, length of impedance tuner on CPW line $l_{14}$, and width of impedance tuner for dipole $w_{4}$ are key parameters of the proposed antenna due to their dominant effects on the

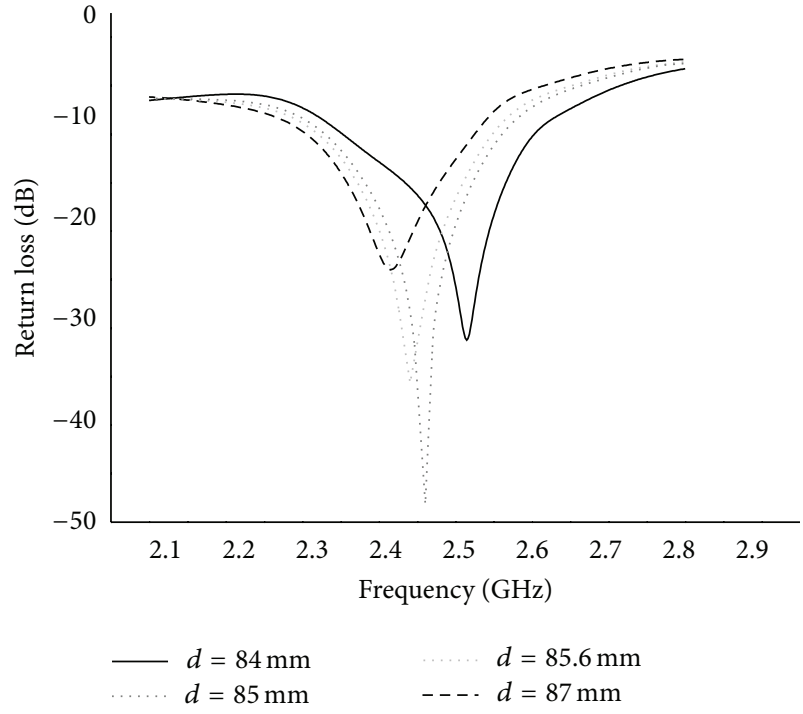

(a)

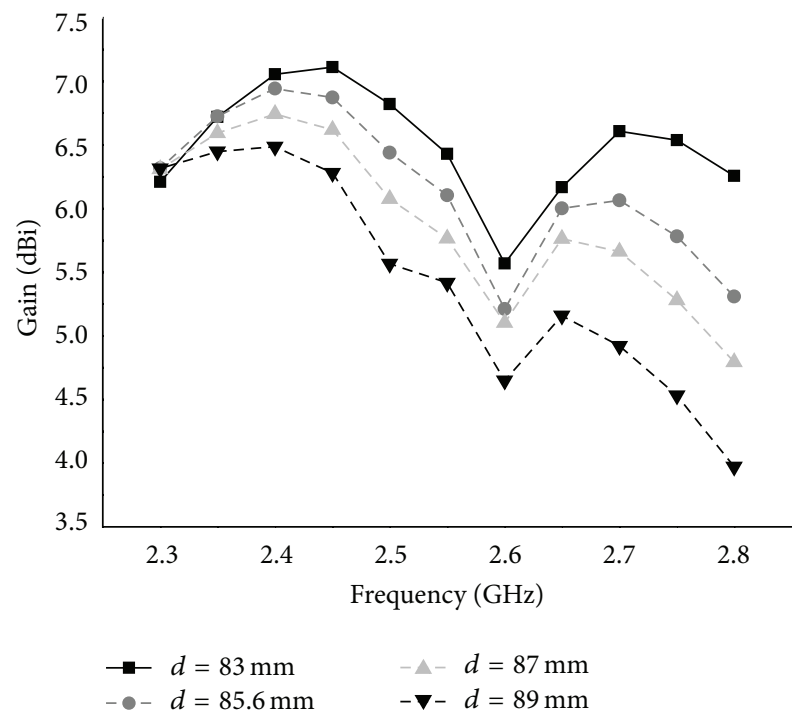

(b)

FIGURE 4: Array distance $d$ effect on simulated return loss and simulated gain of four-element arrays without additional ground. (a) $d$ effect on simulated return loss and (b) $d$ effect on simulated gain.

antenna resonant frequency. Figure 4(a) shows the simulated return loss and Figure 4(b) shows the simulated gain for different array distance $d$ values with other parameters fixed. It can be concluded that decreasing array distance $d$ enhances the total realized gain in the range from $2.3 \mathrm{GHz}$ to $2.8 \mathrm{GHz}$. Distance $d$ also controls antenna impedance matching and resonant frequency. Figure 5 shows the effect of $l_{14}$ on return loss. It can be noticed that length of impedance tuner on CPW has a remarkable effect on resonant frequency. Figure 6 shows the effect of $w_{4}$ on impedance matching.

After optimization by HFSS, main parameters of arrays with maximum gain by different arraying forms in $915 \mathrm{MHz}$ and $2.45 \mathrm{GHz}$ are shown in Table 2. Final parameters of the 


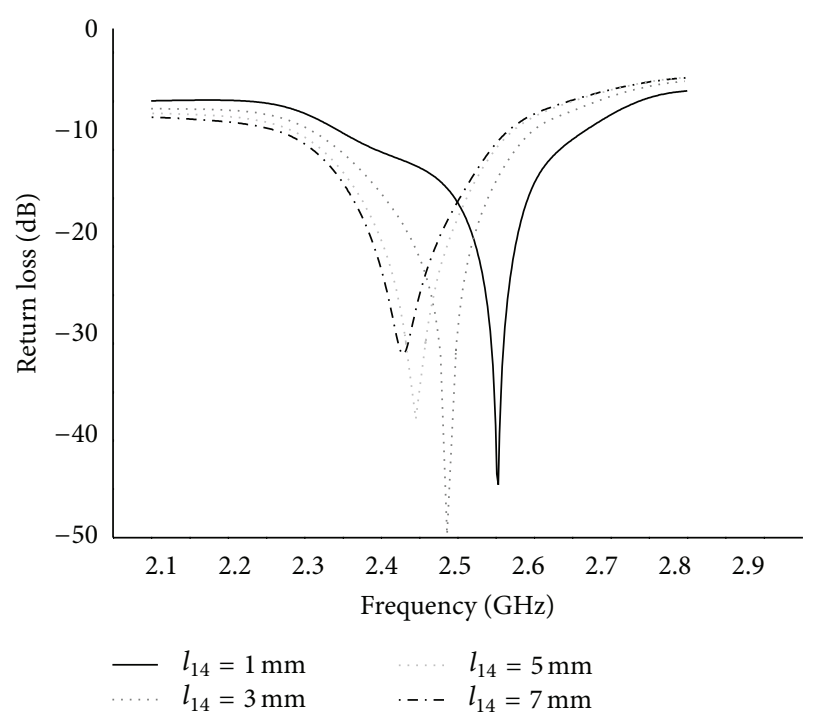

FIGURE 5: Length of CPW line impedance tuner $l_{14}$ effect on simulated return loss of four-element arrays without additional ground.

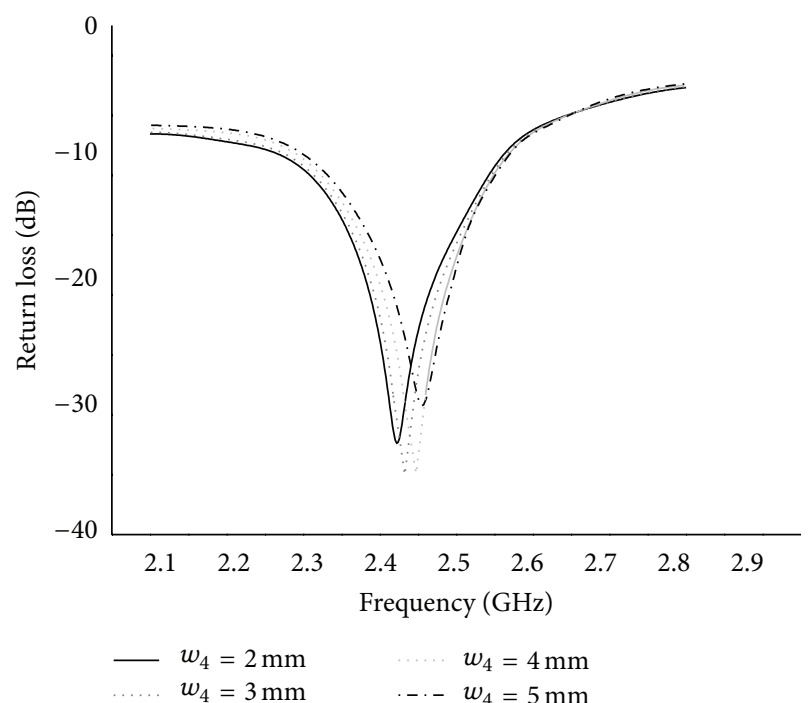

FIGURE 6: Width of dipole impedance tuner $w_{4}$ effect on simulated return loss of four-element arrays without additional ground.

proposed four-element arrays without additional ground in $2.45 \mathrm{GHz}$ are optimized as follows: $l=60 \mathrm{~mm}, d=85.6 \mathrm{~mm}$, $d_{e}=67.3 \mathrm{~mm}, l_{e}=7.2 \mathrm{~mm}, w=90 \mathrm{~mm}, l_{1}=153.6 \mathrm{~mm}, w_{1}=$ $24 \mathrm{~mm}, w_{2}=7 \mathrm{~mm}, w_{3}=2.5 \mathrm{~mm}, w_{4}=4 \mathrm{~mm}, w_{5}=0.8 \mathrm{~mm}, w_{6}$ $=1 \mathrm{~mm}, w_{7}=3 \mathrm{~mm}, w_{8}=2 \mathrm{~mm}, w_{9}=0.8 \mathrm{~mm}, w_{10}=0.8 \mathrm{~mm}$, $w_{11}=0.7 \mathrm{~mm}, w_{12}=3.5 \mathrm{~mm}, l_{2}=21.2 \mathrm{~mm}, l_{3}=23.1 \mathrm{~mm}, l_{4}=$ $4.6 \mathrm{~mm}, l_{5}=21.9 \mathrm{~mm}, l_{6}=4 \mathrm{~mm}, l_{7}=30.3 \mathrm{~mm}, l_{8}=30.5 \mathrm{~mm}$, $l_{9}=31.1 \mathrm{~mm}, l_{10}=22.5 \mathrm{~mm}, l_{11}=6 \mathrm{~mm}, l_{12}=5 \mathrm{~mm}$, and $l_{13}=$ $0.3 \mathrm{~mm}$.

Fabricated antenna with additional ground is shown in Figure 7. The bottom layer of antenna is $15 \mathrm{~mm}$ above additional ground. Simulated and measured return loss results are shown in Figure 8. Figure 8(a) presents simulated

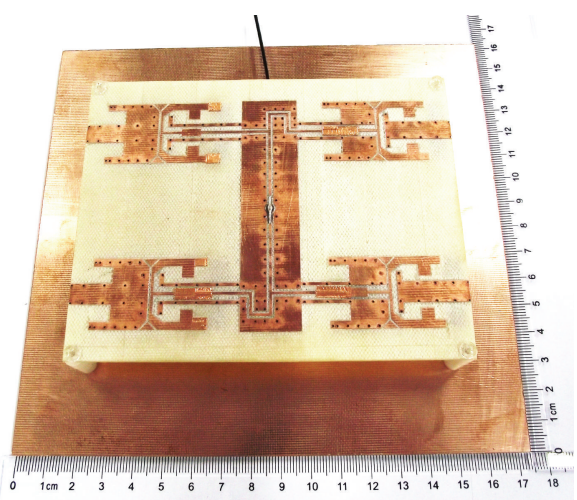

FIGURE 7: Fabricated antenna with additional ground.

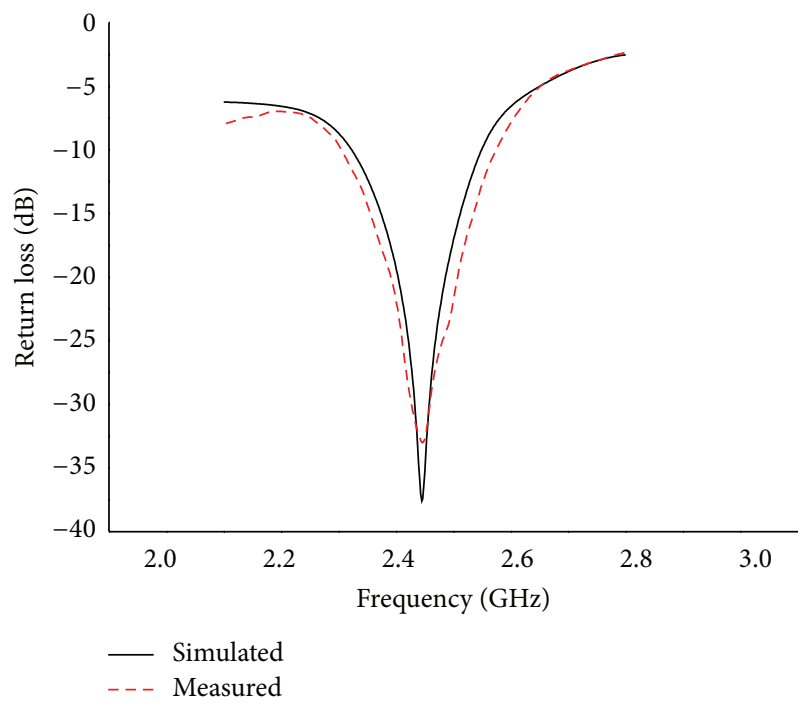

(a)

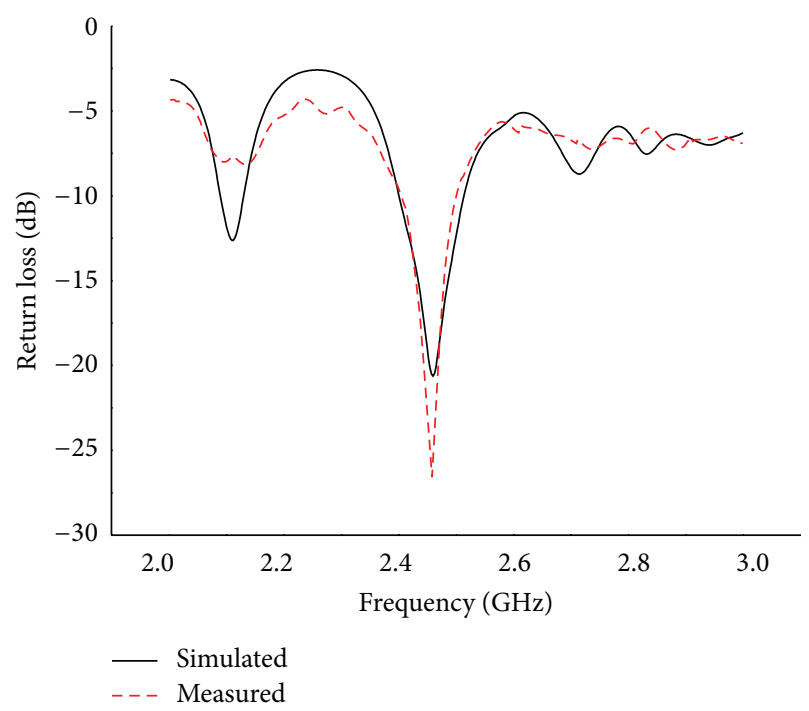

(b)

FIGURE 8: Simulated and measured return loss. (a) Without additional ground and (b) with additional ground. 


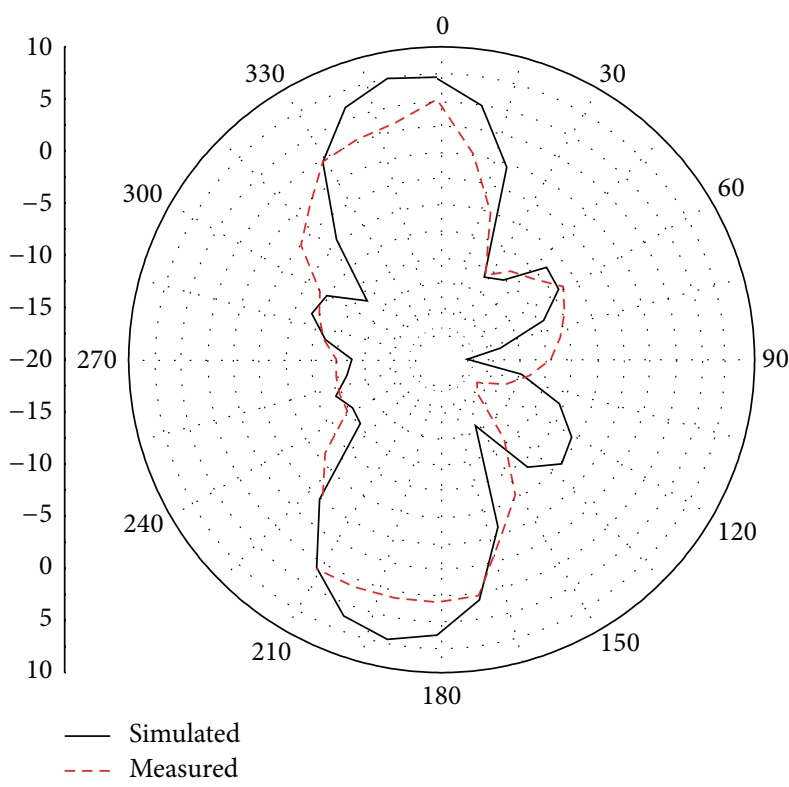

(a)

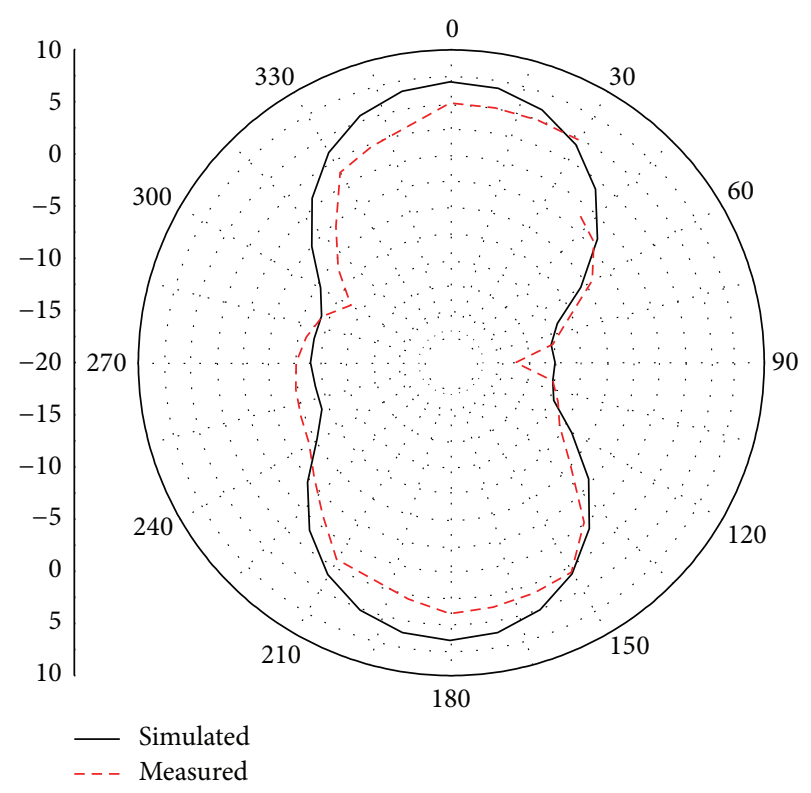

(b)

Figure 9: Simulated and measured radiation pattern. (a) E-plane and (b) H-plane.

TABLE 2: Values of main parameters.

\begin{tabular}{lcccc}
\hline $\begin{array}{l}\text { Resonant } \\
\text { frequency }\end{array}$ & Arraying form & $d_{e}(\mathrm{~mm})$ & $d(\mathrm{~mm})$ & $l(\mathrm{~mm})$ \\
\hline $915 \mathrm{MHz}$ & $\begin{array}{l}\text { Two-element } \\
\text { (no ground) }\end{array}$ & 173.5 & 200.4 & - \\
$2.45 \mathrm{GHz}$ & $\begin{array}{c}\text { Four-element } \\
\text { (no ground) }\end{array}$ & 67.3 & 85.6 & 60 \\
$2.45 \mathrm{GHz}$ & $\begin{array}{c}\text { Four-element } \\
\text { (with ground) }\end{array}$ & 57.1 & 79.2 & 60 \\
\hline
\end{tabular}

return loss without additional ground. The $-10 \mathrm{~dB}$ band is from $2.32 \mathrm{GHz}$ to $2.55 \mathrm{GHz}$. After installing additional ground, return loss decreases to $-19 \mathrm{~dB}$ and the bandwidth reduces to $110 \mathrm{MHz}$ as shown in Figure 8(b). Measured result basically tallies with simulated result, and the bandwidth meets the requirements of RFID $2.45 \mathrm{GHz}(2.400 \mathrm{GHz}-$ $2.483 \mathrm{GHz}$ ). The radiation patterns in E-plane and $\mathrm{H}$-plane are shown in Figure 9. The main lobe of E-plane radiates in vertical direction, verifying the method discussed before. Simulated and measured gains are shown in Figure 10. After installing additional ground, gain approximately increases by $3 \mathrm{dBi}$. Simulated gain of four elements without additional ground at $2.45 \mathrm{GHz}$ bandwidth ranges from $6.6 \mathrm{dBi}$ to $7 \mathrm{dBi}$. With additional ground, simulated gain increases to $9.9 \mathrm{dBi}$. Measured gain without additional ground is from $5.9 \mathrm{dBi}$ to $7.5 \mathrm{dBi}$ and with additional ground is from $9.1 \mathrm{dBi}$ to $10.5 \mathrm{dBi}$ within bandwidth. The simulated and measured gains are approximately the same and meet the requirements of RFID $2.45 \mathrm{GHz}$ high-gain base station antenna.

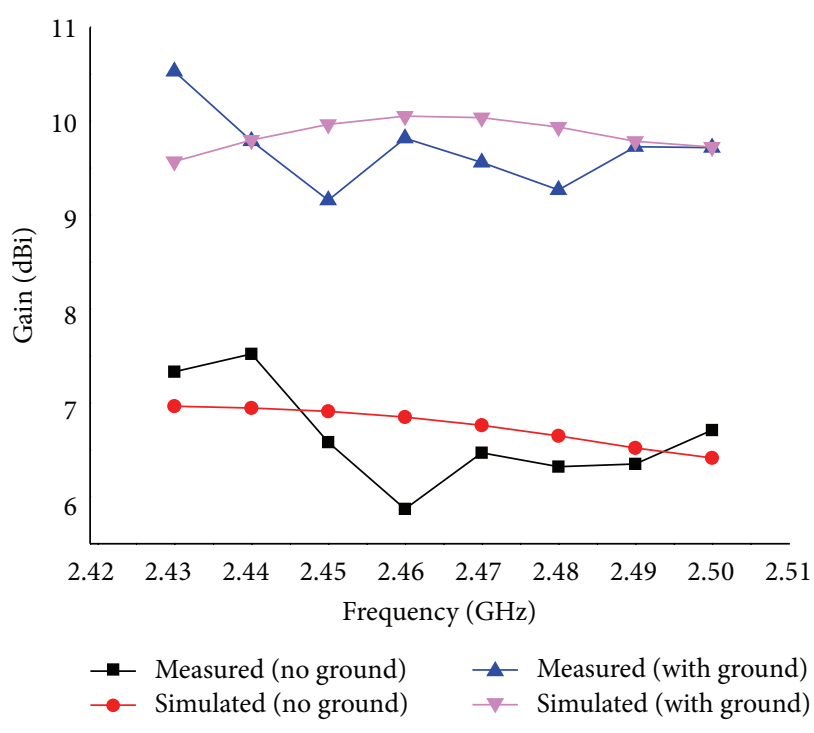

FIGURE 10: Simulated and measured gain.

\section{Conclusion}

This paper presents a design method of high-gain planar dipole-array antenna for $2.45 \mathrm{GHz}$. Gain is enhanced due to the same direction of current by reversing phase of two adjacent ports. By setting phase retardation of each array, radiation direction is controllable. Expressions of two and four elements are given and radiation pattern is calculated by MATLAB. Simulated return loss at resonant point is $-35.3 \mathrm{~dB}$ with gain up to $7 \mathrm{dBi}$. Simulated gain with additional 
ground is up to $9.9 \mathrm{dBi}$. The maximum measured gain without additional ground is $7.5 \mathrm{dBi}$ and with additional ground is $10.5 \mathrm{dBi}$. In general, the proposed planar dipole-array antenna is suitable for $2.45 \mathrm{GHz}$ high-gain base station antenna with characteristics of high gain, controllable direction, and planarity.

\section{Conflict of Interests}

The authors declare that there is no conflict of interests regarding the publication of this paper.

\section{Acknowledgments}

This work was supported in part by the Suzhou Key Laboratory for Radio and Microwave/Millimeter Wave under Grant no. SZS201110, in part by the Natural Science Foundation of Jiangsu Province under Grant no. BK20130326, in part by the National Natural Science Foundation of China under Grant no. 61301076, and in part by the Natural Science Foundation of the Higher Education Institutions of Jiangsu Province under Grant no. 12KJB510030.

\section{References}

[1] J. Landt, "The history of RFID," IEEE Potentials, vol. 24, no. 4, pp. 8-11, 2005.

[2] R. Weinstein, "RFID: a technical overview and its application to the enterprise," IT Professional, vol. 7, no. 3, pp. 27-33, 2005.

[3] Y. Z. Yu, H. N. Yang, and Z. Y. Huang, "A novel dual-band tag antenna for rfid application," Applied Mechanics and Materials, vol. 427, pp. 1289-1292, 2013.

[4] L. Xueguan and G. Huiping, Microwave Technology and Antennas, Xi'dian University Press, Xi'an, China, 2007.

[5] S. A. Patil and R. Gupta, "Effect of small patches on gain of stacked high gain wide band antenna," International Journal of Emerging Trends in Electrical and Electronics, vol. 2, no. 3, pp. 91-94, 2013.

[6] K. Fujimoto and J. R. James, Mobile Antenna Systems Hdbk 2E, Artech House Publishers, 2001.

[7] S. Lin, Y. C. Lin, X. Liu, M. Q. Liu, X. R. Ma, and L. Jing, "A composite dipole antenna array with direct feed," Progress in Electromagnetics Research C, vol. 34, pp. 253-263, 2013.

[8] Y. Q. Zhang, J. W. Rong, X. Li, L. Yang, and S. X. Gong, "Novel wideband omnidirectional antenna for wireless applications," Progress in Electromagnetics Research C, vol. 40, pp. 257-267, 2013.

[9] H. A. Elsadek, "CLIP antenna for wireless bluetooth applications," IEEE Antennas and Propagation Magazine, vol. 47, no. 3, pp. 149-153, 2005.

[10] J. Row, "A simple impedance-matching technique for patch antennas fed by coplanar microstrip line," IEEE Transactions on Antennas and Propagation, vol. 53, no. 10, pp. 3389-3391, 2005.

[11] J. D. Kraus and R. J. Marhefka, Antenna for All Applications, McGraw Hill, Upper Saddle River, NJ, USA, 2002. 

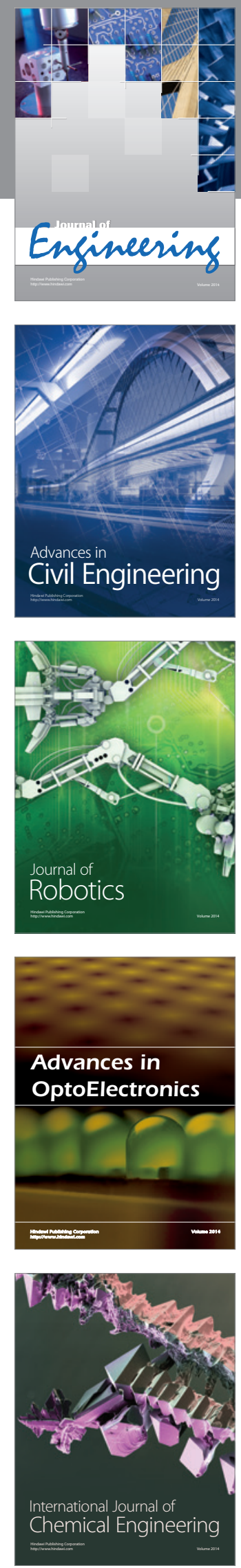

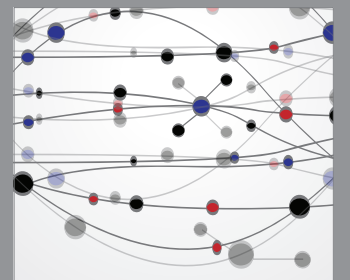

The Scientific World Journal
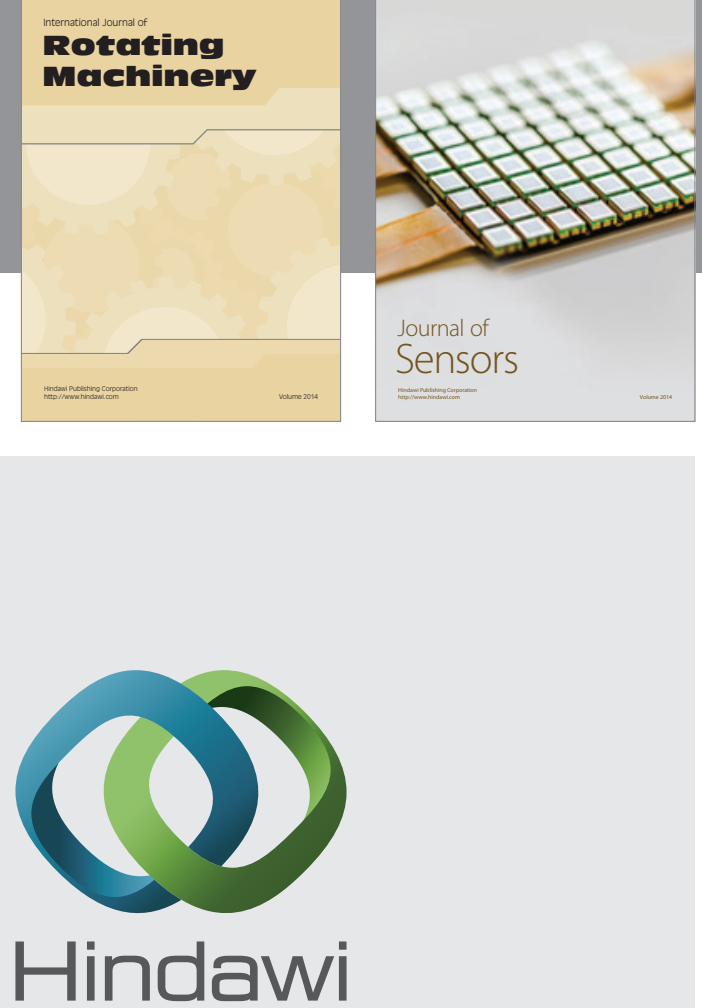

Submit your manuscripts at http://www.hindawi.com
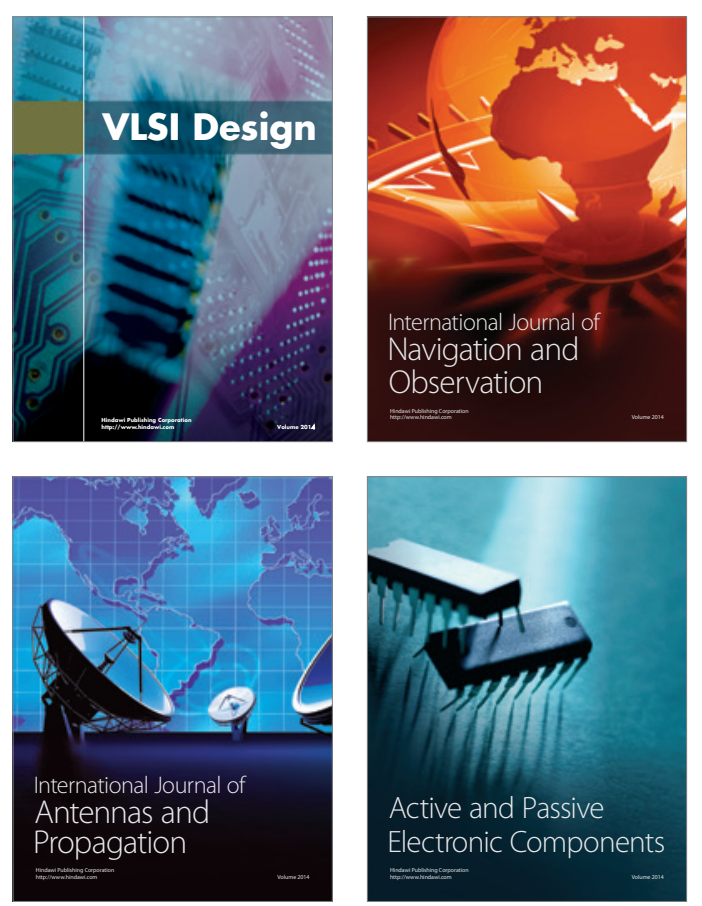
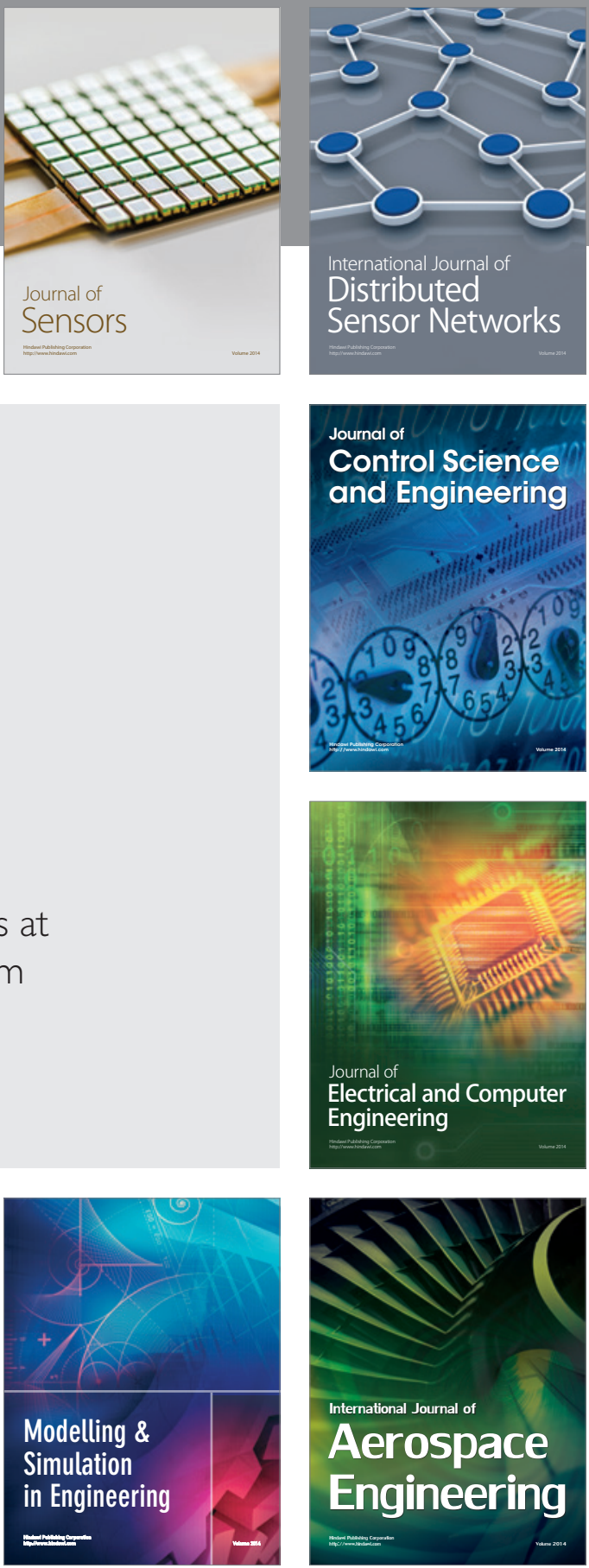

Journal of

Control Science

and Engineering
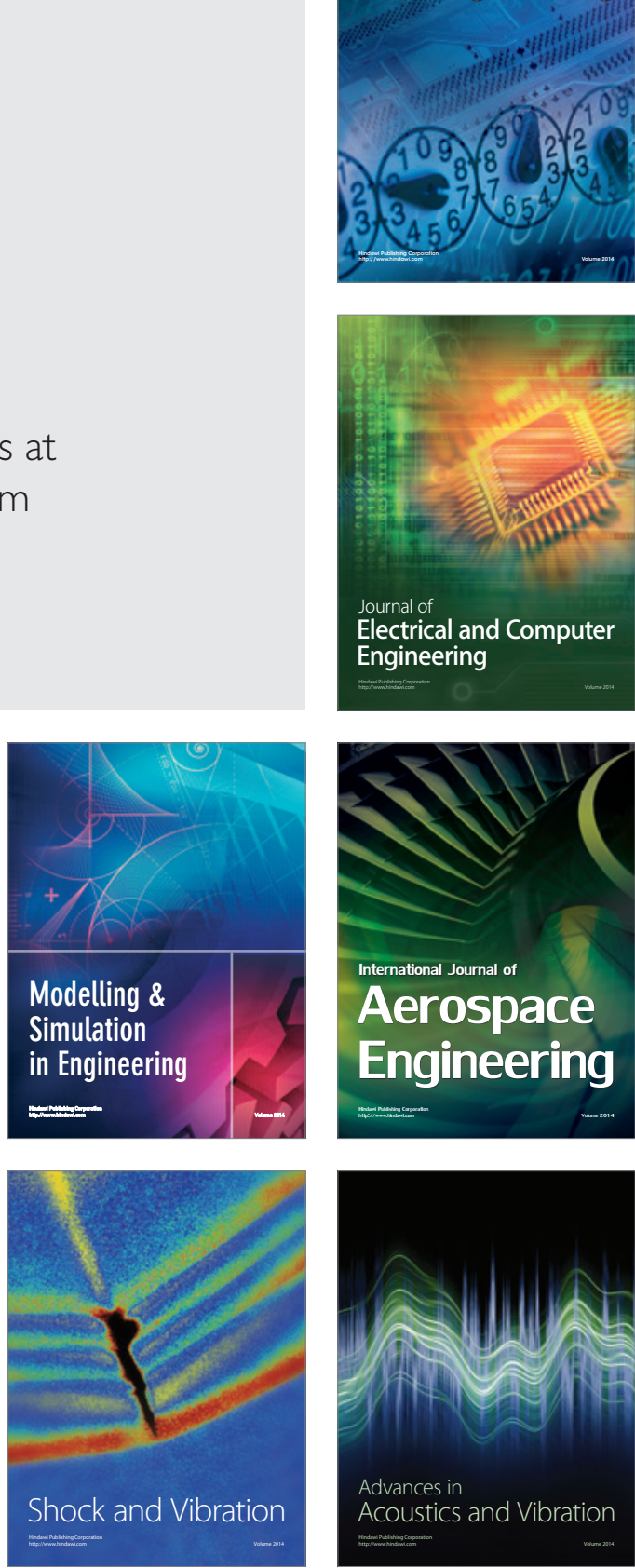